\title{
A Case of Behcet's Disease Complicated with a Pulmonary Artery Aneurysm and Deep Vein Thrombosis, Separately
}

\author{
Jae Min Lee, Jemma Ahn, Young Jae Hwang, Seung Han Kim, Jong Su Lee, \\ Sung Jae Choi, Young Ho Lee, Jong Dae Ji, Gwan Gyu Song
}

Division of Rheumatology, Department of Internal Medicine, Korea University Medical College, Seoul, Korea

\begin{abstract}
Behcet'sdisease is a chronic inflammatory disease characterized by oral ulcers, genital ulcers, uveitis, and skin lesions. Furthermore, Behcet's disease can manifest as vascular lesions, such as, those of vasculitis, venous thrombosis, or thrombophlebitis or as an arterial aneurysm. Here, the authors report the case of a pulmonary artery aneurysm and deep vein thrombosis in a 41-year-old woman with a previous diagnosis of Behcet's disease. The patient presented with hemoptysis and a cough, and was found to
\end{abstract}

\section{Introduction}

Behcet's disease is a chronic, systemic, inflammatory disease of unknown origin. Its major clinical manifestations are oral ulcers, genital ulcers, uveitis, and skin lesions, and its other manifestations are multiple arthritis, gastrointestinal lesions, central nervous system involvement, and vascular lesions. Small or large vessel vasculitis in Behcet's disease leads to vessel occlusion or aneurysm formation (1), but arterial involvement occurs infrequently and presents as aortitis or a peripheral arterial aneurysm with arterial thrombosis. The pulmonary artery is the second most common site of arterial involvement in Behcet's disease (2), and pulmonary artery aneurysms can cause massive hemoptysis by rupture in bronchi. Venous thrombosis is also present in one-fourth of Behcet's disease patients, and deep venous thrombosis of the lower limb is the most frequent venous manifestation. Few cases of Behcet's disease in a female patient combined with have a bleeding pulmonary artery aneurysm at the right lower lung. Pulmonary arteriography was performed and the aneurysm was embolized with coils. As a result, hemoptysis did not subsequently recur. However, five years later, deep vein thrombosis occurred in the left leg. Left leg pain improved after the regional infusion of thrombolytics.

Key Words. Behcet's disease, Pulmonary artery aneurysm, Endovascular embolization, Deep vein thrombosis

a pulmonary artery aneurysm and deep venous thrombosis have been reported (3). In this article, we describe a case of Behcet's disease that was complicated by a pulmonary artery aneurysm and deep venous thrombosis, separately occurred with 5 years interval.

\section{Case Report}

A 41 year-old woman was admitted with a 2-month history of hemoptysis and sustained cough. Initially, amount of hemoptysis was small manifesting as blood-tinged sputum. Four hours before admission, she presented $30 \mathrm{~mL}$ of fresh hemoptysis accompanying with intractable cough. The patient had been diagnosed with Behcet's disease about 4 years previously. Her diagnosis was based on oral ulcers, genital ulcers and pathergy test. She was being treated with colchicine $1.2 \mathrm{mg}$ per day and Dapsone $25 \mathrm{mg}$ per day. The patient was a non-smoker and did not consume alcohol regularly. On phys-

\footnotetext{
<Received : December 19, 2011, Revised (1st: February 24, 2012, 2nd: April 2, 2012), Accepted : April 4, 2012> Corresponding to : Young Ho Lee, Division of Rheumatology, Department of Internal Medicine, Korea University Anam Hospital, Korea University College of Medicine, 126-1, Anam-dong 5-ga, Seongbuk-gu, Seoul 136-705, Korea. E-mail : lyhcgh@korea.ac.kr
} 
ical examination, vital signs were stable, but respiratory sounds were decreased in the right lower lung field. A peripheral blood examination revealed; hemoglobin $10.2 \mathrm{~g} / \mathrm{dL}$, hematocrit $32.6 \%$, platelet count $545,000 / \mu \mathrm{L}$, erythrocyte sedimentation rate (ESR) $47 \mathrm{~mm} / \mathrm{hr}$, and C-reactive protein (CRP) $19.7 \mathrm{mg} / \mathrm{dL}$. Biochemical analyses of blood showed no pathological findings. Prothrombin and partial thromboplastin times were normal. But HLA-B51 test was not executed. Chest radiography showed an ill-defined increased opacity in the right lower lung (Figure 1), and a computerized tomography $(\mathrm{CT})$ scan of the thorax with intravenous contrast revealed a round enhancing lesion, measuring $2.2 \times 2.0 \mathrm{~cm}$, in right lower lung (Figure 2). The lesion was connected to the



Figure 1. Chest X-ray showing ill-defined increased opacity in the right lower lung.

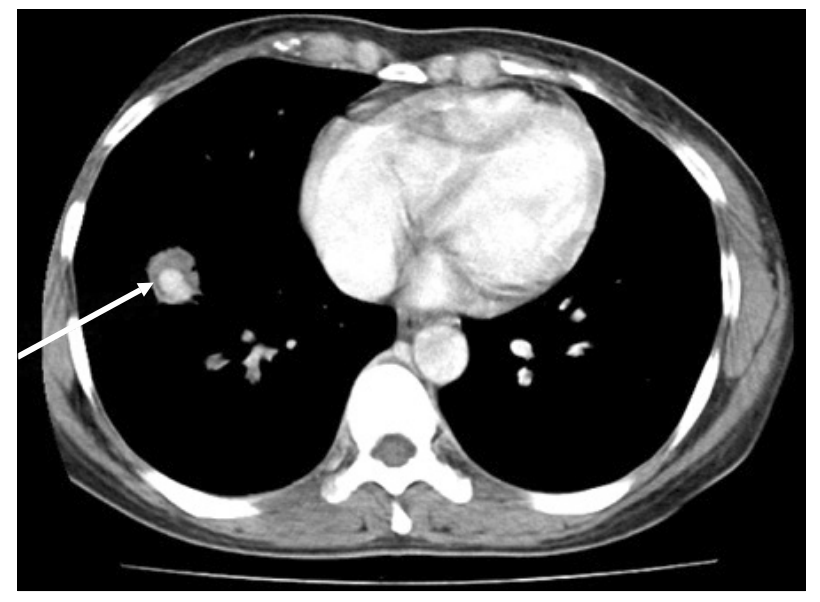

Figure 2. Contrast computerized tomography (CT) scan of the thorax showing a round enhancing lesion, measuring $2.2 \times 2.0 \mathrm{~cm}$ in size, in the right lower lung (arrow). pulmonary artery, and a hypo-dense lesion was seen in the proximal pulmonary artery. Pulmonary artery angiography was performed for diagnosis and treatment. A pulmonary artery aneurysm and broncho-pulmonary shunt was demonstrated at lateral segment of right lower lung. The aneurysm was embolized with two $6 \mathrm{~mm} \times 14 \mathrm{~cm}$ coils (NESTER, Cook, USA) and eight $4 \mathrm{~mm} \times 14 \mathrm{~cm}$ coils (NESTER, Cook, USA) (Figure 3). After coil embolization, methylprednisolone was administered during 3 days at $1 \mathrm{~g}$ per day delivered by intravenous boluses. After steroid pulse therapy, intravenous methylprednisolone was changed to oral prednisolone $55 \mathrm{mg}$ (1 $\mathrm{mg} / \mathrm{kg}$ ) per day. Post-procedural recovery was uneventful, and the patient was discharged eight days after embolization. The patient was treated with a combination of cyclophosphamide and prednisolone after discharge in an outpatient clinic. Cyclophosphamide was administered as monthly intravenous boluses of $1 \mathrm{~g}$ and oral prednisolone was tapered from $55 \mathrm{mg}$ to $5 \mathrm{mg}$ over 10 months. Cyclophosphamide was continued for 6 months and then changed to azathioprine $100 \mathrm{mg}$ per day. Because of the possibility of a hemorrhagic complication, anticoagulant medication was not given.

Five years after discharge, the patient was transferred to emergency room with left leg pain presumed to be due to deep vein thrombosis in the left lower limb. Laboratory tests showed; hemoglobin $12.9 \mathrm{~g} / \mathrm{dL}$, platelets $399,000 / \mu \mathrm{L}$, WBC $8,400 / \mu \mathrm{L}$, prothrombin time $86 \%$, partial thromboplastin time 38.4 seconds, ESR $36 \mathrm{~mm} / \mathrm{hr}$, CRP $15.4 \mathrm{mg} / \mathrm{dL}$ and D-dimer increased to $0.83 \mu \mathrm{g} / \mathrm{mL}$. Protein $\mathrm{C} / \mathrm{S}$ activity and antigen levels was within normal range. Lupus anticoagulant was negative, but antiphospholipid antibody $\operatorname{IgG} / \operatorname{IgM}$ was not tested.

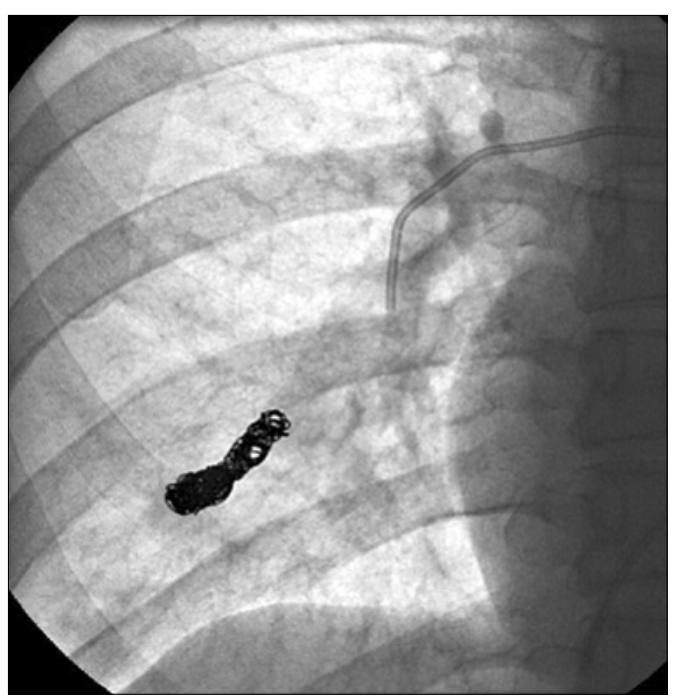

Figure 3. Pulmonary arteriograph showing Nester coils in the pulmonary artery aneurysm. 


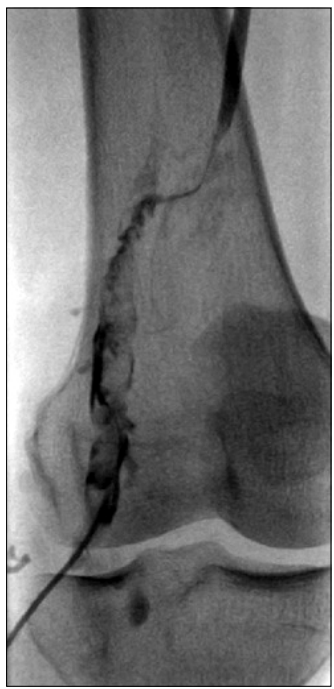

Figure 4. Lower extremity venograph showing a thrombus in the left popliteal vein and the catheter used for the peripheral venous approach.

CT angiovenography revealed a thrombus in the left superficial femoral vein and popliteal vein (Figure 4). IVC filter (OPTEASE, Cordis, USA) insertion was performed for endovascular management. After filter insertion, loading dose of urokinase 100,000 IU and heparin 5,000 IU was infused through the distal portion of the left popliteal vein. After infusing regional thrombolytics, the remnant thrombus was manually removed. Two weeks later, IVC filter was removed. Leg pain and swelling improved after flow-directed regional thrombolytic therapy, and there were no evidence of a secondary pulmonary embolism or bleeding. After discharge, she was treated with azathioprine $100 \mathrm{mg}$ per day and colchicine $1.2 \mathrm{mg}$ per day for 3 months, and no evidence of hemoptysis recurrence was encountered after pulmonary artery embolization, warfarin was administered for 3 months, and then changed to aspirin. At 6 months after discharge, the patient remained asymptomatic with no recurrence of the leg pain.

\section{Discussion}

Behcet's disease is a chronic, systemic, inflammatory disease. Its major manifestations are recurrent oral and genital aphthous ulcerations. Furthermore, Behcet's disease may involve neurologic, cardiovascular, pulmonary, and musculoskeletal systems, and cardiovascular manifestations have been described in 7 49\% of patients. Veins are frequently affected, and their involvements result in both superficial thrombophlebitis and deep venous thrombosis in $30 \sim 40 \%$ of patients. Arterial complications occur in $1 \sim 7 \%$ of patients and pulmonary artery involvement is observed in $1 \%$ (4-6).
Men are much more likely to be affected by arterial disease. Pulmonary artery aneurysm has a poor prognosis and is one of the leading causes of death in Behcet's disease patients. Hemoptysis, when massive and untreated, has a mortality rate of $>50 \%$ (7). Medical treatments based on steroids and on immunosuppressive drugs, such as cyclophosphamide or azathioprine, have been tried, but although some have reported successful treatment results and aneurysmal regression for immunosuppressive treatments $(8,9)$, embolization with medical therapy more widely accepted (10). Surgical treatment may be considered for refractory vessel disease.

Venous thrombosis of the lower extremities and superior or inferior vena cava occlusion frequently occur in Behcet's disease patients. Unfractionated heparin and anticoagulation historically represent the mainstay treatment for deep vein thrombosis, but anticoagulation therapy cannot be used in patients with a high risk of hemorrhagic complications. Thus, anticoagulation therapy can be administered via flow-directed regional thrombolytic therapy, which is based on the direct regional infusion of concentrated thrombolytic agent from an ipsilateral peripheral vein into the deep venous system (11). Because secondary pulmonary embolism due to small fragments can occur, IVC filtration must be performed before direct regional thrombolytic therapy.

Immunosuppressive agents are recommended for the management of acute deep vein thrombosis in Behcet's disease, but anticoagulation is not recommended by the EULAR guidelines (12). The 'vasculo-Behcet' concept has been adopted when vascular complications dominate clinical features (13). There is some debate about use of non-soluble coil or soluble gelfoam. In this case, pulmonary artery aneurysm was treated successfully by coil embolization and deep vein thrombosis was treated by regional thrombolytics infusion. Because of coexistence bleeding risk and thrombotic complication, we must concern to determine treatment in vasculo-Behcet's disease. The early detection of vascular lesions and appropriate treatment are essential for the optimal care of these patients.

\section{References}

1. Cil BE, Geyik S, Akmangit I, Cekirge S, Besbas N, Balkanci F. Embolization of a giant pulmonary artery aneurysm from Behcet disease with use of cyanoacrylate and the "bubble technique". J Vasc Interv Radiol 2005;16: 1545-9.

2. Erkan F, Kiyan E, Tunaci A. Pulmonary complications of Behçet's disease. Clin Chest Med 2002;23:493-503.

3. Kim YG, Ko HK, Ko OB, Kim TS, Kim HW, Lee CK, et al. Bronchial artery embolization for massive hemoptysis in a patient with Behcet's disease. J Korean Rheum 
Assoc 2005;12:311-4.

4. Kural-Seyahi E, Fresko I, Seyahi N, Ozyazgan Y, Mat C, Hamuryudan $\mathrm{V}$, et al. The long-term mortality and morbidity of Behçet syndrome: a 2-decade outcome survey of 387 patients followed at a dedicated center. Medicine (Baltimore) 2003;82:60-76.

5. Hamuryudan V, Er T, Seyahi E, Akman C, Tüzün H, Fresko I, et al. Pulmonary artery aneurysms in Behçet syndrome. Am J Med 2004;117:867-70.

6. Atzeni F, Sarzi-Puttini P, Doria A, Boiardi L, Pipitone N, Salvarani C. Behçet's disease and cardiovascular involvement. Lupus 2005;14:723-6.

7. Jean-Baptiste E. Clinical assessment and management of massive hemoptysis. Crit Care Med 2000;28:1642-7.

8. Tunaci M, Ozkorkmaz B, Tunaci A, Gül A, Engin G, Acunaş B. CT findings of pulmonary artery aneurysms during treatment for Behçet's disease. AJR Am J Roentgenol 1999;172:729-33.

9. Lê Thi Huong D, Wechsler B, Papo T, Piette JC, Bletry
O, Vitoux JM, et al. Arterial lesions in Behçet's disease. A study in 25 patients. J Rheumatol 1995;22:2103-13.

10. Swanson KL, Johnson CM, Prakash UB, McKusick MA, Andrews JC, Stanson AW. Bronchial artery embolization: experience with 54 patients. Chest 2002;121:789-95.

11. Sharafuddin MJ, Sun S, Hoballah JJ, Youness FM, Sharp WJ, Roh BS. Endovascular management of venous thrombotic and occlusive diseases of the lower extremities. J Vasc Interv Radiol 2003;14:405-23.

12. Hatemi G, Silman A, Bang D, Bodaghi B, Chamberlain AM, Gul A, et al. Management of Behçet disease: a systematic literature review for the European League Against Rheumatism evidence-based recommendations for the management of Behçet disease. Ann Rheum Dis 2009;68: 1528-34.

13. Calamia KT, Schirmer M, Melikoglu M. Major vessel involvement in Behçet's disease: an update. Curr Opin Rheumatol 2011;23:24-31. 